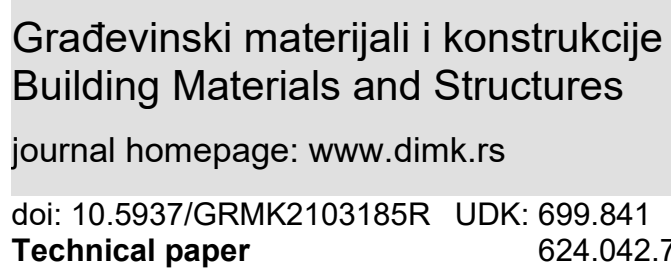

\title{
Comparative analysis of conventional and new seismically isolated structure*
}

\author{
Jelena Ristić( ${ }^{* 1)}$, Miloš Vučinić2), Danilo Ristić( ${ }^{3)}$, Milutin Vučinić() \\ 1) Faculty of Engineering, Department of Civil Engineering, International Balkan University (IBU), Skopje, R.N.Macedonia \\ 2) Institute for Construction, Sima Barovića 16-18, Podgorica, Montenegro \\ 3) Institute of Earthquake Engineering and Engineering Seismology (IZIIS), Ss Cyril and Methodius University, Skopje, R.N.Macedonia \\ 4) GP Planum, Beograd, DSD, Podgorica, Veljka Vlahovića 24
}

\section{Article history}

Received: 19 July 2021

Received in revised form: /

Accepted: 25 August 2021

Available online: 30 September 2021

Keywords

Earthquake,

building,

seismic isolation,

energy dissipation,

nonlinear model

seismic safety

\begin{abstract}
Extensive analytical and experimental research has been done by the authors directed to mitigation of the effects of earthquakes on structures. The research results mainly represent parts of the realized several related international projects. A selected part of the analytical studies directed to comparison between conventional and seismically isolated frame structures is presented in this paper. The responses of the applied newely developed advanced seismic isolation system HC-RMS-GOSEB to the simulated input excitation of three representative earthquakes of intensity $0.50 \mathrm{~g}$, have shown that it is very effective for construction of vibro-isolated and seismically resistant buildings, providing activated multistage seismic response and globally optimized seismic energy balance. Its application achieves an increase in the vibration period of the structure, far enough from the dominant period of seismic excitation. The results of the research confirm that this system is a potential solution for achieving low-cost and highly efficient protection of buildings.
\end{abstract}

\section{Introduction}

Important technological advances and innovations have been created by the authors based on conducted long-term original analytical and experimental research within several international projects, [1], [4-19], focused on efficient mitigation of earthquake effects upon engineering structures. Our studies have been planned and realized considering the most recent analytical advances, [3] \& [20], and suitable experimental modeling developments, [2], in this specific field. Presently, the authors are briefly introducing the new specific study results obtained from their recent analytical investigations realized for the purpose of comparison between the main prerequisites regarding construction of seismically safe conventional and innovative seismically isolated RC building structures. The favorable behavior of the applied innovative isolation system HC-RMS-GOSEB under strong input excitation caused by three earthquakes with intensity PGA $=0.50 \mathrm{~g}$ has pointed out that this system is very efficient in construction of vibro-isolated and seismically resistant buildings, enabling an activated multistage seismic response and a globally optimized seismic energy balance. The application of this system enables an increase of the vibration period of a structure and avoidance of the range of dominant periods of seismic excitation. The research results have proved that this system represents a potential, widely applicable solution for achievement of low-cost and very efficient protection of existing and new high-rises. This paper shows the representative part of the comparative results obtained from the performed extensive analytical investigations of the dynamic behavior, the seismic safety and the construction cost of a selected prototype residential structure constructed in Skopje, treating the structure alternatively, first as a structure originally built as a conventional system and then as a structure seismically isolated by application of the originally conceptualized new HC-RMS-GOSEB system.

\section{Description of the prototype structure}

The building consists of a basement, a souterrain, a ground floor and 5 storeys, with an outline: basement, souterrain and ground floor $68.00 \times 18,50 \mathrm{~m}$, gross area of $1258,00 \mathrm{~m}^{2}$ at plan, Fig. 1. The external dimensions of the characteristic storey are $69,80 \times 20,90$, gross area 1371,00 $\mathrm{m}^{2}$ at plan. The total area of the structure is $3 \times 1258+5 \times 1371$ $=10629,00 \mathrm{~m}^{2}$. The storey heights of the basement and the souterrain are $2,65 \mathrm{~m}$. The storey heights of the ground floor and the characteristic storey are $3,20 \mathrm{~m}$ and $2,88 \mathrm{~m}$, respectively.

\footnotetext{
* Paper presented at ASES 2020 Symposium, Arandjelovac, Serbia, May 2021.

Corresponding author:

E-mail address: risticjelenaibu@gmail.com, jelena.ristic@ibu.edu.mk
} 


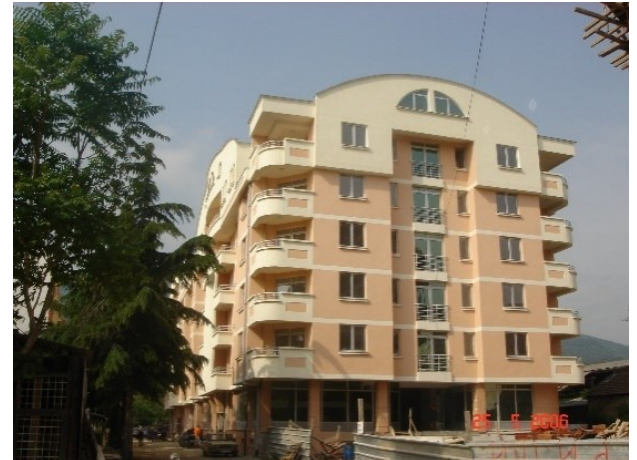

Figure 1. View of the analyzed constructed prototype structure in Skopje

Due to its considerably large length, the structure is dilatated into two equal segments of which only one has been analyzed, but the final conclusions refer to both. The main structural system consists of a reinforced concrete 3D frame structure with frames in both orthogonal directions. The staircase area is bounded by reinforced concrete walls. To prevent the negative torsional effect of seismic forces, walls up to half module are inserted at the ends of the structure. The basement and the souterrain walls are constructed of reinforced concrete. The foundation plate has a thickness of $80 \mathrm{~cm}$. All reinforced concrete walls have a thickness of $25 \mathrm{~cm}$. The façade walls are of a "sandwich" type and have a thickness of $30 \mathrm{~cm}$, while the inner walls are constructed of brick blocks with a thickness of $12 \mathrm{~cm}$. The reinforced concrete columns are proportioned $50 \times 60 \mathrm{~cm}$ in the basement and $50 \times 70 \mathrm{~cm}$ in the souterrain. At the ground floor, they are round $\varnothing 55 \mathrm{~cm}$, while their proportions at the storeys are $50 \times 50 \mathrm{~cm}$. The reinforced concrete beams are proportioned $50 \times 40 \mathrm{~cm}$. The floor structure represents a reinforced concrete slab with a thickness of $16 \mathrm{~cm}$ at the basement and the souterrain. Its thickness at the storeys is $14 \mathrm{~cm}$ as is also the thickness of the skew roof and staircase slabs. The walls and the slabs are reinforced by meshed reinforcement, with the exception of the foundation slab that is reinforced with ribbed reinforcement. The beams and the columns are reinforced with ribbed reinforcement of quality RA-400/500-2. The concrete class used for all elements is $30 \mathrm{MPa}$. The bearing capacity of soil is $0,30 \mathrm{MPa}$. The location of the structure belongs to seismic zone of degree IX according to the MCS scale. Figure 1 shows the view of the constructed building.

\section{Seismic responses of the conventional system}

a) Linear mathematical model-0 (MO) of the conventional system: The linear mathematical model M0 of the conventional system of the structure has been formulated and analyzed by means of the SAP2000 software, where "frame" elements have been used to model the reinforced concrete beams and columns, while "shell" elements have been used to model the reinforced concrete slabs and walls, Figure 2. Using the standard design procedure according to the current regulations, seismic analysis of the structural system has been carried out according to the ultimate bearing capacity theory. Based on competent results obtained by use of the SAP2000 software [20], proportioning of all RC elements has been done and the necessary reinforcement has been adopted.

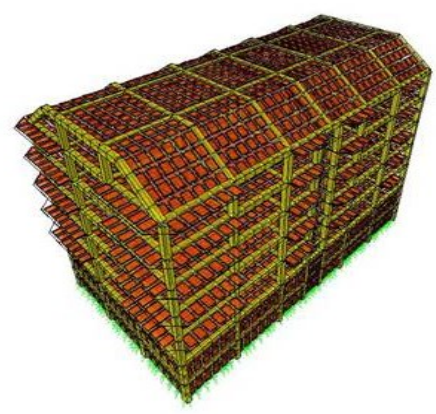

Figure 2. Formulated 3D linear model for analysis of the structure using SAP2000

b) Nonlinear mathematical model-1 (M1) of the conventional system: The experience that has been gathered so far has led to the conclusion that heavy damages or failure of structures under earthquakes take place due to concentration of damage in some critical points of the structures. Such critical points are usually due to inappropriate design of structural elements and their connections at the joints or due to concentration of seismic forces in these and such connections. One of the prerequisites for calculation of the real seismic response of a structure to a certain earthquake record is formulation of a nonlinear model that includes the real nonlinear effects occurring in the structural and nonstructural elements of the structure. On the other hand, such formulated mathematical model should always be sufficiently simple containing, at the same time, an optimal number of degrees of freedom in order to be suitable for realistic analysis of the dynamic response of the system under the effect of selected recorded characteristic earthquakes.

Considering the above, a two-dimensional analytical model of the structure with reduced number of degrees of freedom has been adopted. In regard to the mathematical model for initial linear analysis, all RC walls have been omitted. This has been done for the purpose of obtaining a model for analysis that has the same 3D frame system and will be able to be compared with the new system with seismic isolation HC-RMS-GOSEB that also has the same 3D system, walls being unnecessary. The nonlinear model of the structure has been formulated in the special software programme NORA2005 developed by the third author, [6] The effect of all structural elements and their real distribution along storey heights has been simulated by satisfying the previously described criteria. The mathematical model of the prototype structure has been of the "shear type". For such model, some engineering assumptions have been made. The total mass of the structure is concentrated at the level of the RC slabs, namely at the characteristic nodes of the beams, where the horizontal deformation of the structure is independent of the axial forces in the columns. The nonlinear mathematical model of the conventional system with a fixed base for the selected representative prototype residential building $(G F+5)$ is represented by its two representative RC frames RX3, Figure 3, and RY6, Figure 4. Such formulated mathematical models have served for comparative analysis of economic parameters, i.e., cost of construction, which is the main goal of the brief presentation within this work. 


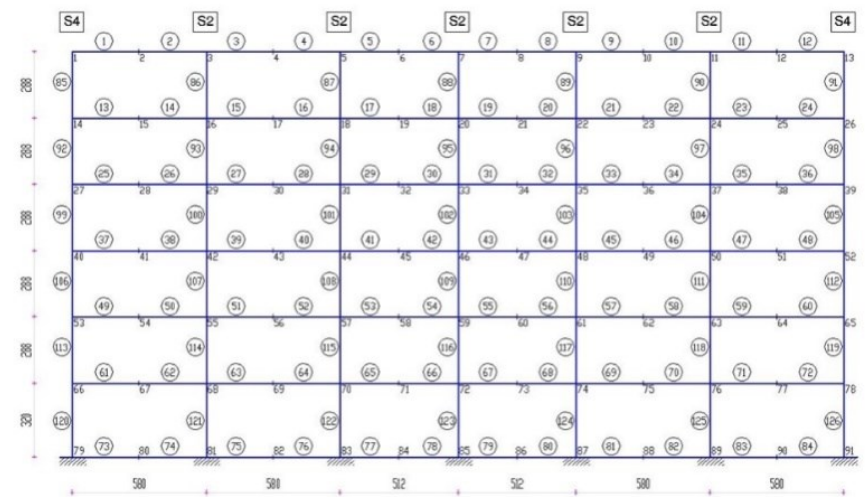

Figure 3. Formulated nonlinear model of the used $R X$ frame of the conventional (C) structure (NORA2005)

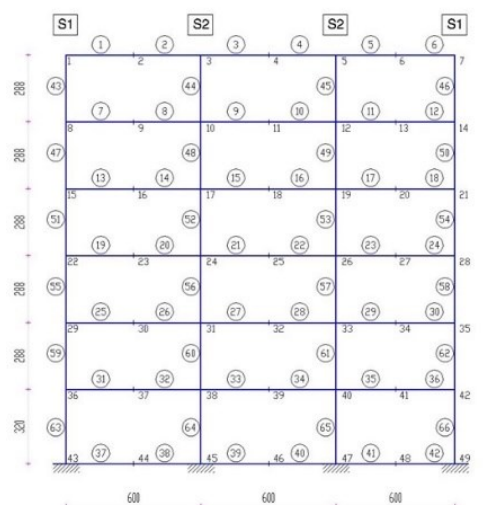

Figure 4. Nonlinear model of the used RY frame of the $C$-structure (NORA2005)
Using the formulated nonlinear mathematical model, all parametric analyses of the seismic response of the conventional structure have been carried out by taking into account the selected three representative earthquake records scaled to several different intensities. For the purpose of realistic modeling of the nonlinear behavior of the structural elements of the building, the well-known complete hysteretic "TAKEDA" model has been used, [6]. The hysteretic "TAKEDA" model is defined by three pairs of data that determine the characteristic points of the skeleton curve: $\mathrm{C}\left(\mathrm{M}_{\mathrm{c}}, \mathrm{F}_{\mathrm{c}}\right) ; \mathrm{Y}\left(\mathrm{M}_{\mathrm{y}}, \mathrm{F}_{\mathrm{y}}\right)$ and $\mathrm{U}\left(\mathrm{Mu}_{\mathrm{u}} \mathrm{F}_{\mathrm{u}}\right)$. The characteristics of the effective distributed nonlinearity of structural elements for each storey have been modeled through predefined real summary $\mathrm{M}-\phi$ diagrams.

\section{Seismic responses of the new HC-RMS-GOSEB system}

The HC-RMS-GOSEB system represents a very efficient system [12], applicable for construction of vibro-isolated and seismically resistant buildings, enabling a multistage seismic response and a globally optimized seismic energy balance. It is based on combined application of optimal seismic isolators and optimal multistage dampers - energy dissipators installed at the base of a structure or in an appropriate space between a defined substructure (lower part) and superstructure (upper part), Figure 5. The objective of the inventive HC-RMS-GOSEB system is to: (a) encourage practical application of a much safer system for construction of vibro-isolated and seismically resistant structures; (b) promote industrialized construction based on optimal components and (c) provide flexible architectural shapes of structures at plan and along height by satisfying the highest standards of the specific architectural requirements. This inventive system enables the achievement of low-cost investment in construction and maintenance of structures during their long serviceability life and exposure to the risk of occurrence of strong earthquakes. The formulated adequate nonlinear mathematical model of the HC-RMS-GOSEB system for the selected representative prototype residential building (GF+5) is presented through the formulated nonlinear models of two representative RC frames, namely RX and RY, Figure 6 and Figure 7.

The applied integral nonlinear model of the new system, Figure 6 and Figure 7, for seismic isolation contains necessary components bellow each column, including both primary base isolators and energy absorbers with activation stages 1 and 2 .
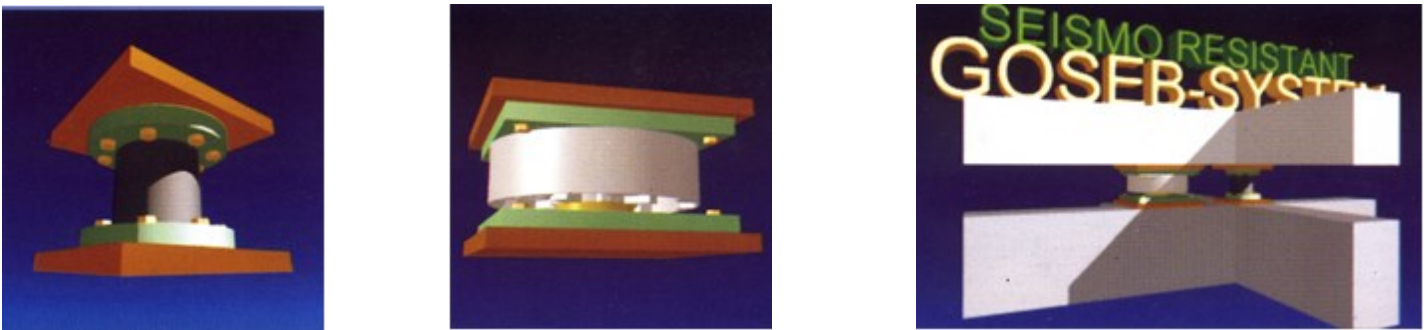

Figure 5. Primary base isolator and energy absorber with view of installation set-up of the two individual components of the invented new isolation (I) HC-RMS-GOSEB system.

The applied new, advanced energy absorbers with two stages of activation, Figure $8 \mathrm{a}$ and Figure $8 \mathrm{~b}$, have originally been developed and experimentally attested, Figure 9, by the first and the third author. The designations in the figures indicate individual, originally defined, components in the descriptions. The appearance and the mode of installation of the components of the HC-RMS-GOSEB system are presented in Figure 5. The comparison between the geometrical and stiffness characteristics of both structural systems has shown that the new, inventive system for seismic isolation HC-RMS-GOSEB, has reduced dimensions of most of its structural elements (RC columns and beams). So, in the new structural system, all RC beams with a crosssection of $50 / 40 \mathrm{~cm}$ are proportioned $30 / 30 \mathrm{~cm}$, while the RC columns at the ground floor proportioned $50 / 60 \mathrm{~cm}$ are proportioned 50/50. In the conventional structural system, 


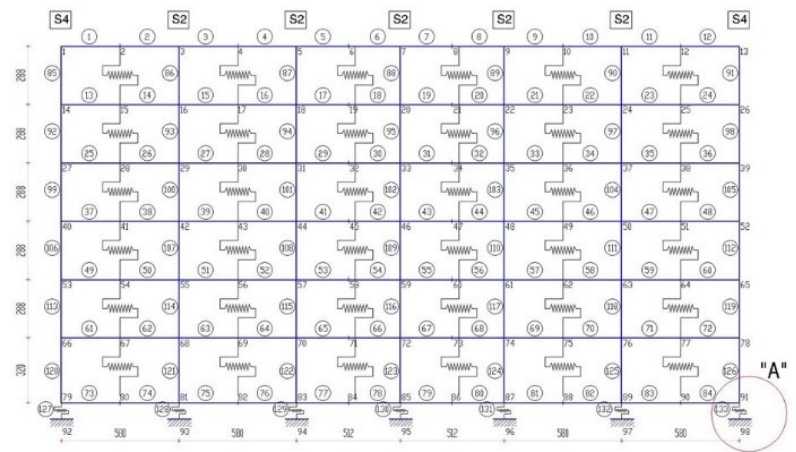

Figure 6. Formulated nonlinear model of the used $R X$ frame of the isolated I-structure (NORA2005)

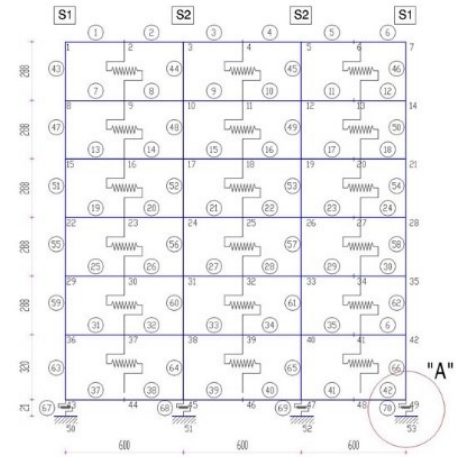

Figure 7. Nonlineardel of the used RY frame of the I-structure (NORA2005) the RC columns extending from the first to the last storey are with a constant cross-section of $50 / 50 \mathrm{~cm}$. In the new system, their cross-section has been reduced as follows: $45 / 45 \mathrm{~cm}$ at the first storey, $40 / 40 \mathrm{~cm}$ at the second storey, $35 / 35 \mathrm{~cm}$ at the third storey and $30 / 30 \mathrm{~cm}$ at the remaining storeys. The new specific nonlinear hysteretic models for simulation of nonlinear behavior of individual components are formulated in the computer software NORA2005, [6]. It is essential to note that the procedure of design of new isolators of structures involves definition of their preliminary stiffness characteristics, dynamic analysis of the isolated structure and final definition of stiffness of the bearings. As an input parameter, it is necessary to define the target period

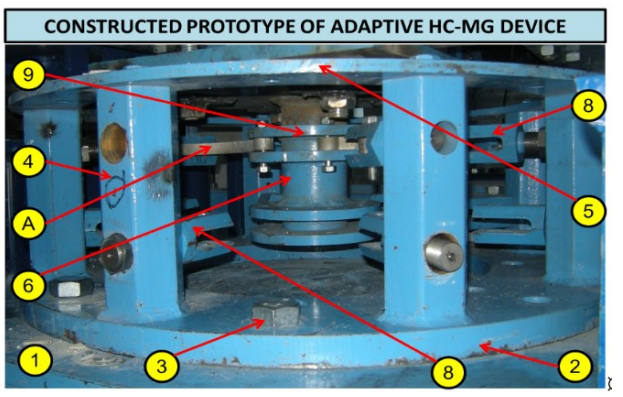

Figure 8a. Original energy absorbers with two stages of activation (Ristic J.; Ristic, D., [17])

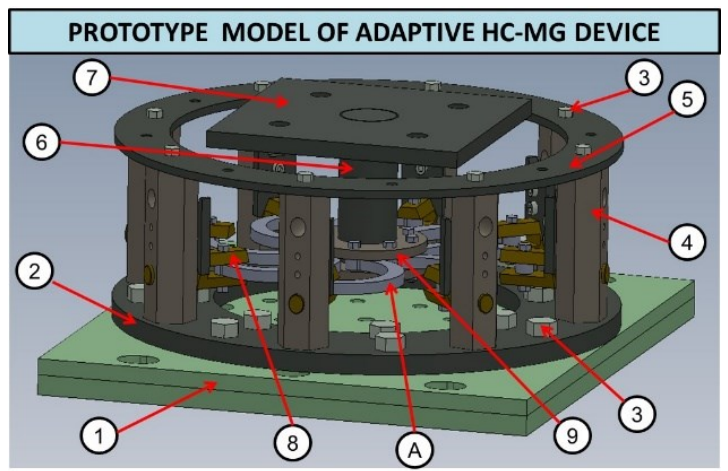

of the structure, namely the period at which the structure exhibits a slight response to a seismic excitation whereat its horizontal displacement at the base should be within the allowable limits. So, for this model, a target period $T_{1}=3,00$ $s$ has been considered. It is known that the intensity of dynamic response of a structure mainly depends on the frequency content of the input excitation and its intensity. To realistically present the dominant frequency content of the expected earthquake ground motions for the considered location of the structure, corresponding knowledge on the regional and particularly local soil conditions is necessary. In some cases, the local soil may cause considerable modification of the input seismic wave.

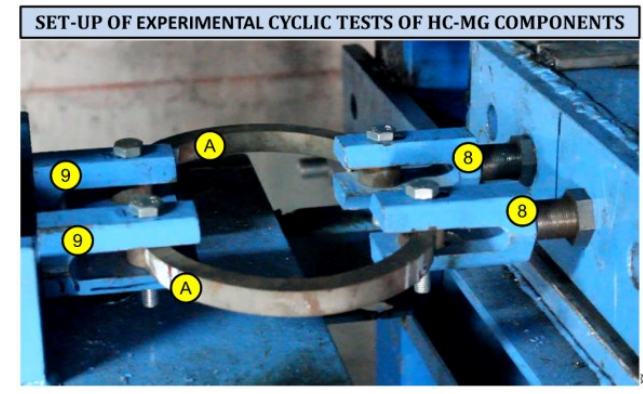

Figure 9. Original attestation of the new energy absorbers (Ristic J.; Ristic, D., [17])

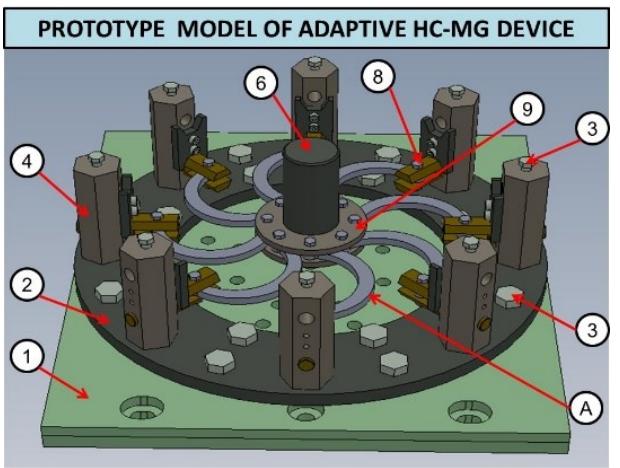

Fig. 8b. Designed experimental prototype model of adaptive HC-MG-device with eight HC-ED components of HC-1.2 type installed at level L1 with gap G1: 1. Bottom fixation plate, 2. Base ring plate, 3. Connecting bolts, 4. Side vertical supports, 5. Upper ring plate, 6. Central support, 7. Upper fixation plate, 8. Gap hinge device, 9. Central hinge device, A. HC-ED components at $L 1$. 
For the presented investigations, some possible options of selecting input excitation have been evaluated. However, a set of three recorded real earthquakes involving a considerably wide range of frequency content has been selected as the most representative input. These are: (a) El Centro, component S00E, USA, 1940; (b) Ulcinj-Albatros, component N-S, Montenegro, 1979; (c) Parkfield, component N85E, USA, 1966 (marked with 1 in fig 10 and 11). To define, as precisely as possible, the occurrence of plastic hinges in the model depending on the intensity of input dynamic excitation, the selected three earthquakes have been scaled to five intensities as follows: $E Q I=0,10 \mathrm{~g}$, $0,20 \mathrm{~g}, 0,30 \mathrm{~g}, 0,40 \mathrm{~g}$ and $0,50 \mathrm{~g}$. This means that $3 \times 5=15$ nonlinear dynamic analyses for one direction, i.e., 30 nonlinear analyses have been done for the conventional model of the integral structure. Also, 30 nonlinear analyses have been carried out for the "isolated" model of the integral structure. More precisely, for the purpose of getting a detailed insight into the characteristics of the dynamic response of both structural systems, a total of 60 nonlinear dynamic analyses have been carried out, processed and analyzed, within the presented ample innovative investigations. The dynamic responses of the model have been defined for the first 20 s at a calculation step of $\mathrm{DT}=0,0005 \mathrm{~s}$. This means that it has been necessary to perform 40000 numerical integration steps to realize a single nonlinear analysis. In the considered case, the analyses of the nonlinear seismic response of the structure have been carried out by successful implementation of the special purpose computer programme NORA2005, developed by the third author [6]. The first three vibration modes of both structural systems for longitudinal x-direction of vibration of the structure are shown in Table 1 . From each nonlinear dynamic analysis, the time responses of physical parameters have been obtained as follows: (1) absolute displacement of nodes; (2) node velocities; (3) node accelerations; (4) global reactions; (5) relative displacements of nonlinear structural and nonstructural elements; (6) hysteretic responses of nonlinear structural and nonstructural elements; (6) hysteretic responses of isolation and energy dissipation elements, and secondary responses. A consecutive procedure involving three steps has been applied. First, analysis of the residential structure $(G F+5)$ in the form of a conventional system with the above stated parameters has been carried out.

Then analysis of the same structure $(G F+5)$ constructed as a HC-RMS-GOSEB structural system has been carried out. Finally, a very detailed comparative analysis of the construction costs and the seismic safety (behavior) of the conventional and the new HC-RSM-GOSEB system has been carried out.

\section{Results: Conventional and HC-RMS-GOSEB system}

The extensive innovative and ample original analytical and experimental investigations discussed and used in this paper were performed during the past longer period [4-19] for the purpose of defining the real potential for practical application of the new HC-RMS-GOSEB system for efficient seismic protection of reinforced concrete and other structures in high rise construction.

Based on the results from the previously conducted studies [12], [17], it has been confirmed that this system enables efficient control of dynamic behavior and successfu protection of structures against the strongest seismic effects. Fig. 10 shows the computed maximum absolute displacements of the conventional and seismically isolated structure

Table 1. The first periods of vibration of the conventional and base isolated HC-RMS-GOSEB system

\begin{tabular}{|c|c|c|c|c|}
\hline \multirow{2}{*}{ Mode } & \multicolumn{2}{|c|}{ Conventional system } & \multicolumn{2}{c|}{ Base isolated system } \\
\cline { 2 - 5 } & $\mathrm{T}(\mathrm{sec})$ & Direction & $\mathrm{T}(\mathrm{sec})$ & Direction \\
\hline 1 & 0.960 & Transverse & 2.962 & Transverse \\
\hline 2 & 0.896 & Longitudinal & 2.934 & Longitudinal \\
\hline 3 & 0.852 & Torsion & 0.452 & Torsion \\
\hline
\end{tabular}

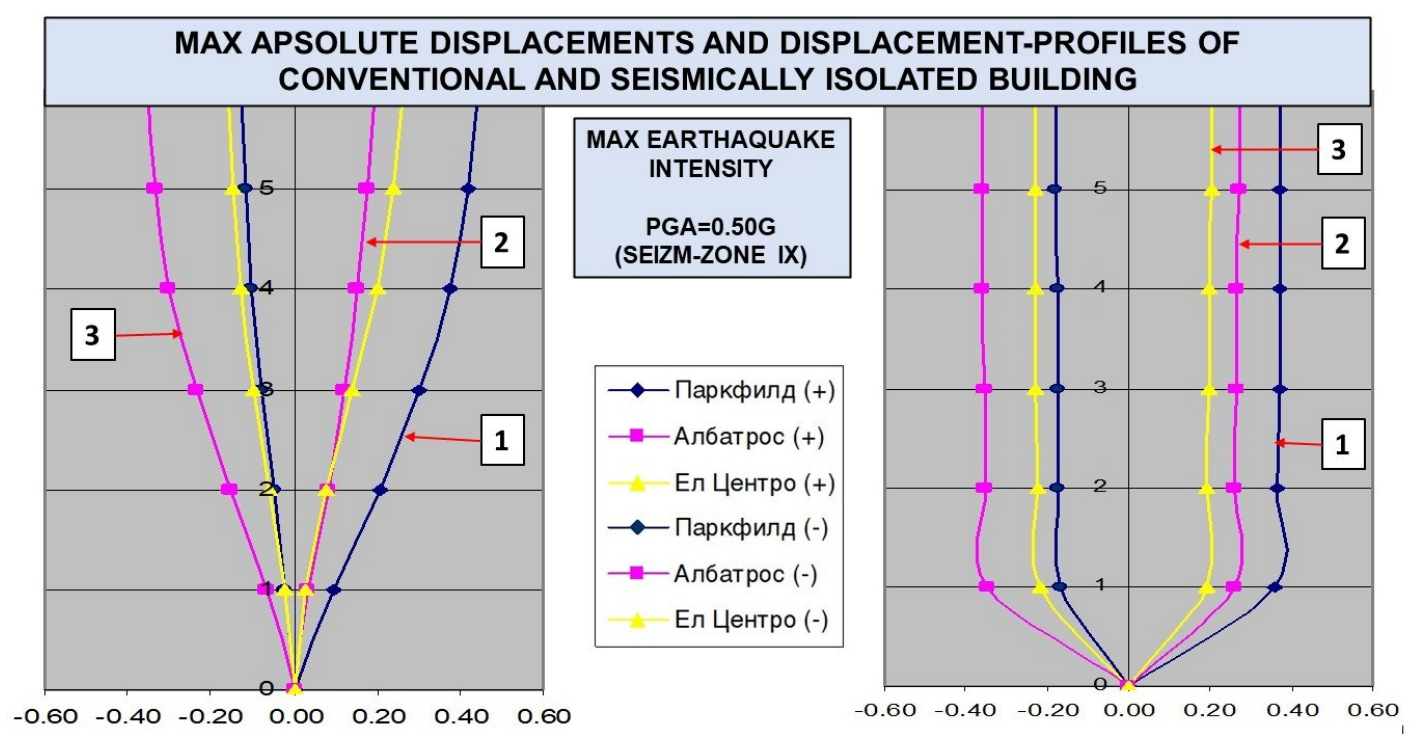

Figure 10. Maximum absolute displacements $(m)$ of the conventional and seismically isolated structure under the effect of three strong earthquakes with maximum intensity $P G A=0.5 \mathrm{~g}$ (zone IX) 


\section{MAX RELATIVE DISPLACEMENTS AND DISPLACEMENT-PROFILES OF CONVENTIONAL AND SEISMICALLY ISOLATED BUILDING}
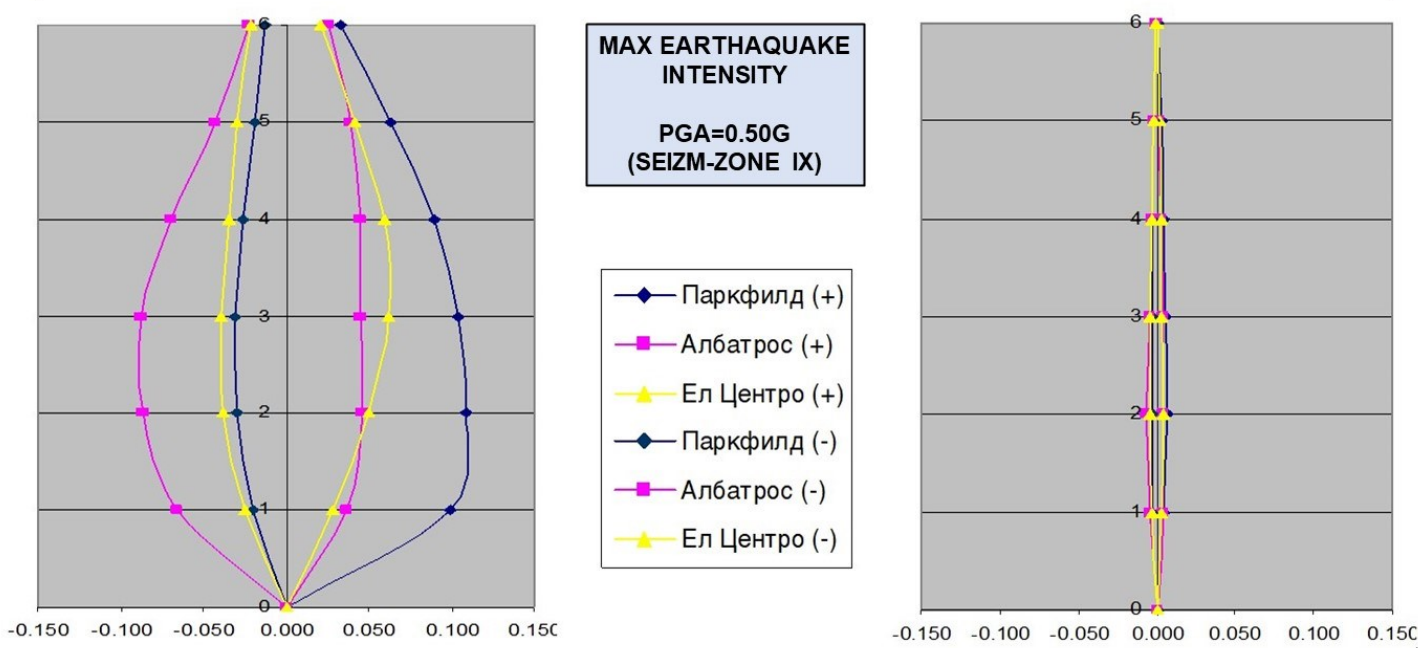

Figure 11. Maximum relative displacements $(m)$ of the conventional and seismically isolated structure due to the effect of three strong earthquakes with maximum intensity $P G A=0.5 g$ (zone IX)

due to the effect of three earthquakes with maximum intensity of $P G A=0.5 \mathrm{~g}$ (zone IX). It can be seen that the conventional system suffers large inter-storey displacements causing extensive damage or total failure of the structure. The use of the new HC-RMS-GOSEB system enables compensation of large displacements by isolators and energy dissipaters located at the base of the structure where all storeys remain completely protected, without any possibility for even fine cracks or damage. The same is also confirmed in Figure 11 that shows the maximum relative displacements of the conventional and seismically isolated structure due to the effect of three earthquakes with maximum intensity PGA $=0.5 \mathrm{~g}$ (zone IX). In both figures, Fig. 10 and Fig. 11, characteristic responses to three different earthquakes are respectively marked, namely, 3 for the considered El Centro earthquake, 2 for the considered UlcinjAlbatros earthquake and 1 for the considered Parkfield earthquake.

The presented characteristics of the seismic response of the seismically isolated structure have been intensively studied and experimentally confirmed, [11] and [12] with the realized extensive program of dynamic testing of the originally constructed model of the new HC-RMS-GOSEB system [17] in the DYN-LAB laboratory of the Institute of Earthquake Engineering and Engineering Seismology (IZIIS), Skopje, Figure 13. A great number of experimental tests have been realized very successfully by means of the achieved very precise simulation of the selected strong real recorded earthquakes on a large seismic shaking table.

In the framework of the study, a particularly important analyzed parameter has been the cost of construction. Therefore, for the analyzed prototype structure, detailed analysis of actual costs of construction has been performed, following the "element by element" procedure. The final results from the completed comparative analysis of the construction cost of the conventional and seismically isolated $\mathrm{RC}$ system are shown in Table 2, and graphically in Figure 12. Detailed descriptions of possible advantages of application of the new HC-RMS-GOSEB system are presented in published lengthy scientific reports, [17]. The authors have particularly been focused on providing a new,.

Table 2. Comparative safety and costs of construction of the RC structural systems of the designed conventional building and the alternatively designed seismically isolated building

COMPARISON OF SAFETY AND COSTS FOR THE BUILDING DESIGNED WITH THE CONVENTIONAL SYSTEM AND WITH THE NEW, SEISMICALLY ISOLATED HC-RMS-GOSEB SYSTEM IN SEISMIC ZONE IX

\begin{tabular}{|c|c|c|c|c|c|c|}
\hline \multicolumn{2}{|c|}{$\begin{array}{l}\text { Type of construction } \\
\text { system of the structure }\end{array}$} & \multirow{2}{*}{$\begin{array}{c}\text { Concrete } \\
\text { (EUR) } \\
305887,29\end{array}$} & \multirow{2}{*}{$\begin{array}{c}\text { Reinforcement } \\
\text { (EUR) } \\
171198,00\end{array}$} & \multirow{2}{*}{$\begin{array}{c}\begin{array}{c}\text { Isolators \& } \\
\text { dissipators } \\
\text { (EUR) }\end{array} \\
0.00\end{array}$} & \multirow{2}{*}{$\begin{array}{c}\text { Total in } \\
\text { (EUR) } \\
477085,29\end{array}$} & \multirow{2}{*}{$\begin{array}{c}\text { Total in } \\
(\%) \\
100.0\end{array}$} \\
\hline S1 & Conventional system & & & & & \\
\hline S2 & RMS-GOSEB system & 163858,31 & 85466,00 & 28000,00 & 277324,31 & 58.12 \\
\hline \multicolumn{2}{|c|}{$\begin{array}{l}\text { Saving due to reduced } \\
\text { material }\end{array}$} & 142028,98 & 85732,00 & $-28000,00$ & 199760.98 & 41.88 \\
\hline
\end{tabular}




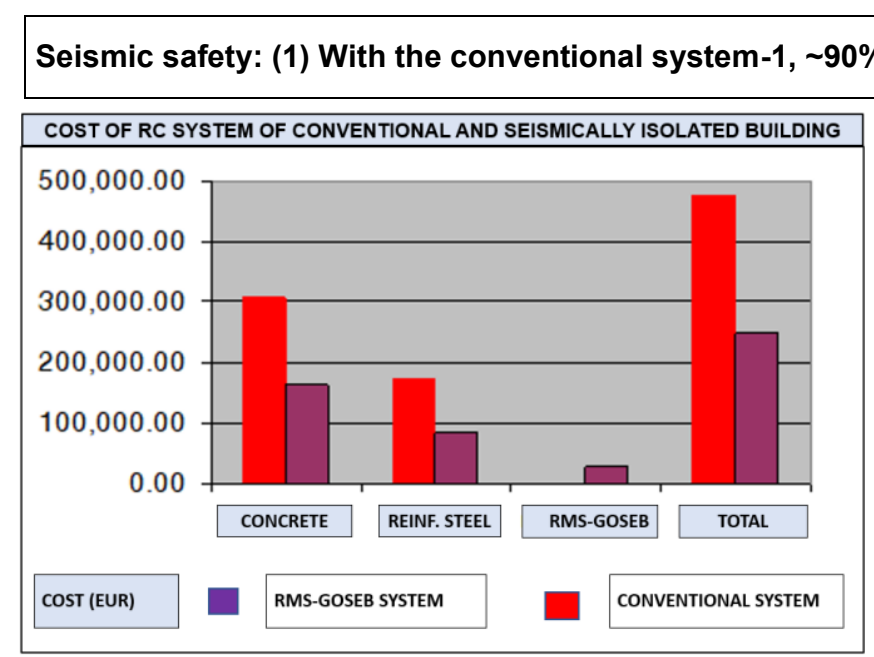

Figure 12. Comparative costs of construction of the alternatively designed $R C$ system of the conventional and seismically isolated building

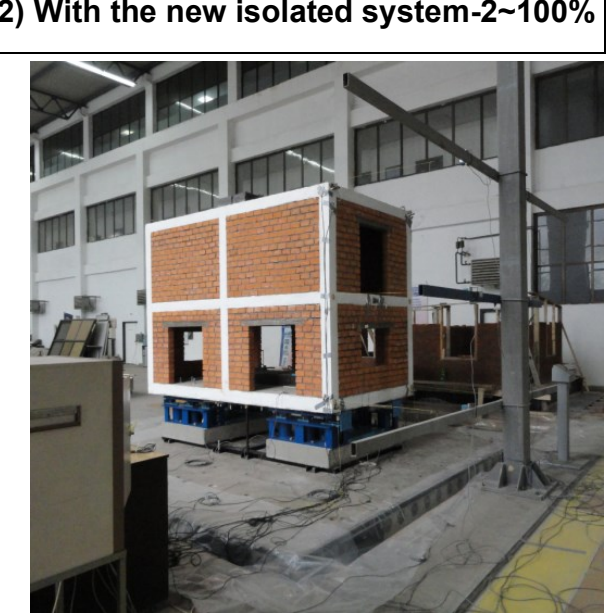

Figure 13. Testing of the HC-RMS-GOSEB system: (Model in DYN-LAB) IZIIS-Skopje) general, human, safe and economical construction technology for the users. Special efforts have been made toward obtaining flexible, durable and advanced structures with defined optionally clear composition and flexible design concept. This can be achieved by application of the HCRMS-GOSEB system, as confirmed by the extensive research experience of the authors and the latest results from the realized investigations. A particular contribution to the recent developments has been made by the first author, who was fully and timely dedicated to innovative work in the field of seismic isolation of bridge structures during the elaboration of her doctoral thesis [12] and continued her research within an international project in the field of development of advanced technologies for seismic isolation of buildings, [17]. The accumulated extensive research results are fully supporting our view that "by building of an isolated structure, we are actually building a seismo-safe structure that possesses high resistance and does not suffer damage under the strongest earthquakes". Today, in most of the developed countries, the method of construction of a conventional structure is most frequently replaced by a new concept of construction of a seismically isolated structure, particularly for structures of some special social importance that have to remain functional even after the strongest earthquakes

Here also belong structures with installed equipment, which is sometimes several times costlier than the construction of the structure itself. Hence, it turns out that investors are somehow forced to increase the level of seismic resistance and safety of structures to protect their investments. The achieved high seismic performances of the new HC-RMS-GOSEB system open the possibilities for consideration of potentials for its future practical application.

\section{HC-RMS-GOSEB System: Powerful technological upgrade}

The basic performance characteristics and advances of the new HC-RMS-GOSEB system developed on the basis of the conducted long-term innovative investigations can be briefly summarized in the following: (1) General process and knowledge gained from the innovative research; (2) Systematization of the design process for the elements of the system; (3) Achieved high reliability regarding quality; (4) Possibilities for creation of industrialized processes.

1. General process and knowledge gained from the innovative investigations: (1) By incorporation of the $\mathrm{HC}$ RMS-GOSEB isolation system, possible occurrence of resonance effects due to the short fundamental period of vibration of the structure exposed to the actual frequency content of the seismic excitation is avoided; (2) Through specific dynamic interaction, the HC-RMS-GOSEB system has a direct contribution to reduction of the vibration transfer between the super- and the sub-structure as a result of the discontinuity of stiffness achieved by incorporation of isolation elements; (3) Despite the reduced proportions and reinforcement of columns and beams, the new HC-RMSGOSEB system is safe even under the highest intensity $(0.50 \mathrm{~g})$ of any of the three representative earthquakes. Unlike this system, in the case of the conventional system, the first "plastic" hinges and exhaustion of bearing capacity of some structural elements occur as early as under intensity of $0,20 \mathrm{~g}$, while total collapse of the structure may take place under peak acceleration of around $0,40 \mathrm{~g}$; (4) The new HCRMS-GOSEB structural system possesses reduced dimensions of its $\mathrm{RC}$ columns and beams in respect to the conventional system; (5) Analyzing the behavior of structures with incorporated isolation HC-RMS-GOSEB system exposed to the effect of even the strongest earthquakes, it has been confirmed that the bearing capacity of the reinforced concrete columns and beams is not exhausted. This statement is supported by the fact that the obtained maximum moments in the columns and the beams are within the limits of the bearing capacity of the cross-section, i.e., the columns and the beams as the main bearing elements of the structure remain in the linear range of behaviour; (6) All necessary design parameters are satisfied. The relative storey displacements are within the allowable limits. The maximum relative storey displacement remains small, the largest being recorded at the second storey, amounting to $d_{\max }=0.0089 \mathrm{~m}$, in the case of the representative frame $R x$ exposed to excitation due to the Parkfield earthquake with intensity $0.50 \mathrm{~g}$. The maximum allowable storey relative displacement is Hstorey $/ 150=0.0192 \mathrm{~m}$, meaning that the expected maximum storey relative displacement will be almost twice less than the allowed value; (7) The maximum absolute displacement of the highest point of the nonlinear 
system amounts to $D_{\max }=0.357 \mathrm{~m}$, for the recorded corresponding shear force of $40.71 \mathrm{kN}$, under the Parkfield earthquake with intensity $0.50 \mathrm{~g}$. Considering that the maximum allowed displacement of the isolators defined by the producer is $0.3800 \mathrm{~m}$, it turns out that safety of the complete isolation system is provided.

2. Systematization of the design process for the system elements: The design process for the new $\mathrm{HC}$ RMS-GOSEB system for control of vibrations and seismic risk reduction is reduced to the following: (1) The selection of dimensions, stiffness and deformability characteristics of the isolation and vibration control elements directly depends on the dynamic and structural characteristics of each individual RC structure; (2) To provide efficient control of the dynamic behavior of RC structures under strong earthquake effects, the applied elements for isolation and seismic energy absorption must be designed with optimally harmonized stiffness and deformability characteristics; (3) The design of the elements of the HC-RMS-GOSEB system can successfully be carried out and verified based on direct dynamic analyses by use of adequate computer programmes developed for that purpose as is, for example, the developed "NORA2005" computer programme, [6] that has been applied for performance of the analytical investigations discussed in this paper; (4) Using commercially available typified elements for isolation and control of vibrations, their practical design for a specific structure can be reduced only to selection of the necessary number of seismic isolators that have the most favourable characteristics for each specific case; (5) From the aspect of practical application, the design and incorporation of the $\mathrm{HC}$ RMS-GOSEB system elements is simple and particularly economically justified since presently, in the era of developed technology, this does not incur extensive costs; (6) The rubber seismic isolation elements of the HC-RMSGOSEB system do not exhibit important modification of their main nonlinear behavior characteristics even under great series of repeated dynamic impacts. Therefore, the main criterion for their possible replacement can be the time period of serviceability-life prescribed in the attests; (7) The results from the performed investigations and the derived conclusions provide the possibility for successful practical application of the HC-RMS-GOSEB system in design of reinforced concrete structures.

3. Achieved high reliability regarding quality: For the new HC-RMS-GOSEB system, high reliability and quality of achieved effect have been confirmed as follows: (1) An adequate seismic protection of structures is provided; (2) Low-cost construction and maintenance of structures during their long serviceability life and exposure to the risk of occurrence of strong earthquakes is achieved.

4. Possibility for creation of industrialized processes: The system enables successful control of dynamic behavior and seismic protection of RC structures in high rise construction even under the strongest earthquakes, enabling: (1) introducing of a much safer system of construction of seismically resistant structures into practice; (2) promotion of industrialized construction based on optimized components and (3) providing flexible architectural shapes of structures in plan and along height satisfying, at the same time, the highest standards related to the specific architetural requirements.

\section{Conclusions}

The original innovative long-term investigations that have been performed so far by the authors can be generally recognized as the first-key-stage of a well targeted and successful innovative work resulting in created new advanced technology characterized by the achieved extraordinary seismic safety, rapid practical applicability and cost-effective construction in seismically active regions. In the next phase, there will be a priority need for creation of conditions for providing complete information to design engineers and investors about the advantages of application of the new innovative HC-RMS-GOSEB system for seismic isolation of RC structures. The need and the justification of application of seismically isolated structures in our region are evident since earthquakes occur randomly without warning, while the new system provides total seismic protection of structures in such cases. In addition, the experience that has been gathered so far in the domain of seismic isolation in highly developed countries is quite great and very positive. The most important benefit from the innovation developments that have taken place so far is the successfully opened scientific-research area that offers innovative and advanced quality solutions for direct practical application in design of seismically safe structures. At the same time, by incorporating the HC-RMS-GOSEB system, a considerable reduction of the seismic risk pertaining to existing and new engineering structures is achieved. In addition, the functionality of the structures, particularly those of vital importance, is increased. The development and innovation research that has been done so far marks the real beginning of a new and long-lasting strategy that practically represents a new potential for high reduction of the seismic risk in the region of Southeast Europe.

\section{Acknowledgement}

The study presented in this paper is mainly based on the original experimental and theoretical results obtained by the authors during successful realization of two recent international innovative projects: (1) Development of System for Protection of Buildings Against Strong Earthquakes with Uniform HS-MG Energy Control, led by the first author [17], representing an international innovative project supported by the European Union, the World Bank and FITR, National Fund for Innovations and Technology Development, Republic of North Macedonia, and (2) Extensive experimental and analytical research that has been performed at IZIIS, Ss. Cyril \& Methodius University, Skopje, in the framework of the three-year innovative NATO Science for Peace and Security Project [12]: Seismic Upgrading of Bridges in South-East Europe by Innovative Technologies (SFP: 983828), with participation of five countries: Macedonia: D. Ristic, Project Leader \& PPD-Director; Germany: U. Dorka, NPD-Director; Albania: A. Lako; Bosnia \& Herzegovina: D. Zenunovic and Serbia: R. Folic. The extended supports from both projects is greatly appreciated. 


\section{References}

[1] Behrami R., Ristic J., Ristic D., Hristovski V., (2019) The New Uniform VF-EnergyDissipation Device: Refined Modelling, 16 World Conference on Seismiclsolation, Energy Dissipation and Active Vibration Control of Structures, 01.07-06.07.2019, St. Petersburg, Russia.

[2] Candeias, P., Costa, A. C., Coelho, E. (2004): Shaking Table Tests of 1:3 Reduced Scale Models of Four-Story Unreinforced Masonry Buildings, 13th World Conference on Earthquake Engineering, Vancouver, Paper: 2199.

[3] Chopra, A., (2016): "Dynamics of Structures", Pearson, 2016.

[4] Misini, M., Ristic, J., Ristic, D., Guri, Z., Pllana, N., (2019) Seismic Upgrading of Isolated Bridges with SFED Devices: Analytical Study Validated by Shaking Table Testing, GRAĐEVINAR, 71 (2019) 4, pp. 255272; https://doi.org/10.14256/JCE.2274.2017.

[5] Misini M., Ristic J., Guri Z., Ristic D., Pllana N., (2021) Upgrading Seismically Isolated Bridges with SpaceFlange Energy-Dissipation Devices, Structures and Buildings, ICE Publishing, January 04, 2021, https://doi.org/10.1680/jstbu.18.00231.

[6] Ristic, D. (1988): Nonlinear Behavior and Stress-Strain Based Modeling of Reinforced Concrete Structures Under Earthquake Induced Bending and Varying Axial Loads, Doctoral Dissertation, School of Civil Engineering, Kyoto University, Japan.

[7] Ristic, D., Kocevski, V., (2006) Evaluation of Economic Feasibility for Application of New Seismic Isolation System for RC Structures, Innovative Emerging Technologies, Institute of Earthquake Engineering and Engineering Seismology (IZIIS), "SS Cyril and Methodius" University, Skopje.

[8] Ristic, D., lemura, H., Ristic, J., (2008) Innovative Seismic Isolation Systems for Buildings Capable of Full Seismic Energy Control, Special Section "Innovative Emerging Technologies", 14th World Conference on Earthquake Engineering, Beijing, China, 1217.10.2008.

[9] Ristic, D., Ristic J. (2012): Advanced Integrated 2G3 Response Modification Method for Seismic Upgrading of Advanced and Existing Bridges, 15th World Conf. on Earthquake Engineering, (WCEE), Lisbon.

[10] Ristic D., Uwe D., Ristic J., (2012) Advanced ML-MD GOSEB Seismic Isolation System for Efficient Seismic Protection of Bridges in South East Europe, 9th German-Japanese Bridge Symposium, Kyoto, Japan, 10-11.09.2012.
[11] Ristic, D. et. all. (2014): Innovative Project, SfP 983828 : Seismic Upgrading of Bridges in South-East Europe by Innovative Technologies (ISU Bridge), International project (5 countries) financed by NATO Programe Science for Peace and Security, Brussels, Belgium.

[12] Ristic, J. (2016) Modern Technology for Seismic Protection of Bridge Structures Applying Advanced System for Modification of Earthquake Response, $\mathrm{PhD}$ Thesis, Institute of Earthquake Engineering and Engineering Seismology (IZIIS), "SS Cyril and Methodius" University, Skopje, Macedonia. (Innovative Project Supported by NATO (Brussels), Science For Peace and Security Program 2010-2014).

[13] Ristic, J., Misini, M., Ristic, D., Guri, Z., Pllana, N. (2017): Seismic Upgrading of Isolated Bridges with SFED Devices: Shaking Table Tests of Large-Scale Model, Gradjevinar, 2147-2017. https://doi.org/10.14256/JCE.2147.2017.

[14] Ristic J., Hristovski V., Ristic D., (2017) "Advanced Seismic Upgrading of Existing Bridges With New Adaptive IMSO-System for Seismic Response Modification", 16th World Conference on Earthquake Engineering, 09.01-13.01.2017, Santiago, Chile.

[15] Ristic J., Hristovski V., Ristic D., (2018) Shaking Table Test of Large-Scale Bridge Model Constructed with New Adaptive IMSO-System for Seismic Protection, 16th European Conference on Earthquake Engineering, 18-21.06.2018, Thessaloniki, Greece.

[16] Ristic J., Ristic D., Behrami R., (2019) The New Uniform VF-Energy Dissipation Device: Prototype Testing", 16 World Conference on Seismic Isolation, Energy Dissipation and Active Vibration Control of Structures, 01.07-06.07.2019, St.Petersburg, Russia.

[17] Ristic, J. (2020) (Author and Project Leader 20192020): System for Protection of Buildings Against Strong Earthquakes with Uniform HS-MG Energy Control, International Innovative Project Supported by European Union, World Bank and FITR, National Fund for Innovations and Technology Development, Republic of North Macedonia.

[18] Ristic J., Brujic Z., Ristic D., Folic R., Boskovic M., (2020) Upgrading of Isolated Bridges with EnergyDissipation Devices: Shaking Table Test, Advances in Structural Engineering, Dec. 17, 2020, ASE-20-0787, https://doi.org/10.1177/13694332211013918.

[19] Ristic J., (2021) Heating and Cooling in Passive Building Design, International Conference of Applied Sciences, Engineering and Mathematics (ICASEM 2021), 03-05.06.2021, IBU, Skopje, Macedonia.

[20] Wilson, E.L., (2002): "Static and Dynamic Analysis of Structures: A Physical Approach with Emphasis on Earthquake Engineering", Computers and Structures Inc. 
